CENTRE FOR EMEA BANKING, FINANCE \& ECONOMICS

Liquidity Risk, Credit Risk and the Overnight Interest Rate Spread: A Stochastic Volatility Modelling Approach

John Beirne

Guglielmo Maria Caporale Nicola Spagnolo

Working Paper Series

No $17 / 11$ 


\title{
Liquidity Risk, Credit Risk and the Overnight Interest Rate Spread: A Stochastic Volatility Modelling Approach
}

\author{
John Beirne $^{\text {a,b }}$, Guglielmo Maria Caporale ${ }^{a, 1}$ and Nicola Spagnolo ${ }^{a}$

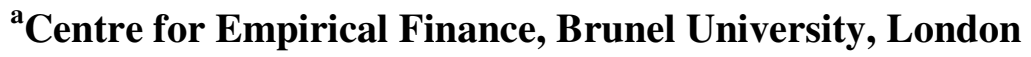 \\ ${ }^{b}$ European Central Bank, Frankfurt
}

\begin{abstract}
In this paper we model the volatility of the spread between the overnight interest rate and the central bank policy rate (the policy spread) for the euro area and the UK during the two main phases of the financial crisis that began in late 2007. During the crisis, the policy spread exhibited signs of volatility, owing to the breakdown in interbank market activity. The determinants of this volatility are assessed using Stochastic Volatility models to gauge the role played by liquidity risk, credit risk (financial and sovereign), and interest rate expectations. Our results suggest that liquidity risk is the main determinant of the volatility of the policy spread, but also that private bank credit risk has become more apparent in the post-Lehman collapse phase of the crisis for the euro area as financial CDS premia rose due to possible default fears. In addition, the ECB appears to have been more effective in addressing liquidity risk since the onset of the crisis, and this may be related to its greater direct access to a broader range of counterparties and its acceptance of a broader range of eligible collateral. The main implication is that, in crisis times, a sufficiently flexible operational framework for monetary policy implementation produces the most timely response to market tensions.
\end{abstract}

Keywords: Overnight Interest Rate Spread, Liquidity Risk, Credit Risk, Stochastic Volatility

We are very grateful to participants in the FRIAS Workshop and Conference on "Information, Liquidity and Trust in Incomplete Financial Markets", held respectively in Eltville am Rhein, Frankfurt, Germany, 15-17 March 2010, and Freiburg, Germany, 11-13 October 2010, for useful comments on an earlier version of this paper. The views expressed in this paper are those of the authors and do not necessarily reflect those of the European Central Bank.

\footnotetext{
1 Corresponding author: Professor Guglielmo Maria Caporale, Centre for Empirical Finance, Brunel University, West London, UB8 3PH, UK. Tel. +44 (0)1895203327. Fax: +44 (0)1895 269 770. E-mail: GuglielmoMaria.Caporale@brunel.ac.uk.
} 


\section{Introduction}

The interbank money market is the primary channel for the implementation of monetary policy for a number of central banks, including, for example, the European Central Bank (ECB) and the Bank of England. Steering overnight interest rates is crucial for these central banks as this provides an anchor for the term structure of interest rates. In the case of the euro area, the Euro Overnight Index Average (EONIA) is a weighted average of all overnight lending transactions between the most active credit institutions in the euro area's money market. Effective steering of the overnight rate by the ECB would therefore imply a low spread between the ECB policy rate and the EONIA rate. Since the intensification of the crisis in October 2008, a very large spread became evident, however. ${ }^{2}$ This coincided with a range of liquidity easing measures by the ECB, leading to a large liquidity surplus across the Eurosystem. While a number of papers have examined the determinants of the EONIA spread in the pre-crisis period, there are very few (if any) that examine the period of the crisis. The purpose of this paper is to investigate this issue, using a Stochastic Volatility modelling approach. While the primary analysis is on the euro area, we will also carry out a comparative analysis for the UK, which also adopted enhanced liquidityproviding measures to counteract the lack of interbank market activity caused by the crisis.

In non-crisis times, excess volatility is not prevalent in the overnight interest rate as it tracks closely the main central bank policy rate, so that the spread between both is relatively low (i.e. less than five basis points). ${ }^{3}$ In crisis times, however, this is not necessarily the case, and in the recent crisis there has been a clear rise in both the level and volatility of the overnight interest rate spread. Clearly, in circumstances when volatility is higher, so too is uncertainty associated with the spread. During the recent crisis of 2007 to 2009, as liquidity dried up, a large policy spread was observed, particularly after the collapse of Lehman Brothers in mid-September 2008. This triggered an intensification of the crisis, and an expansion of central bank balance sheets as liquidity-providing measures were introduced. The result was a large liquidity surplus. In the case of the euro area, the EONIA rate fell below the minimum bid rate (MBR) in the MRO (main refinancing operations), as opposed to non-crisis times when EONIA normally trades above the MBR rate - see Figures A1 and A2 in the Appendix for more details.

Previous work that focuses on explaining the overnight interest rate spread is relatively limited, while to the knowledge of the authors there exists no study aiming to explain the spread in the crisis of 2007 to 2009. Regarding the EONIA spread, Nautz and Offermanns (2008) examined volatility transmission in the European money market over the period 2000 to 2006, specifically assessing the transmission of EONIA volatility to longer term money market rates. In estimating the time-varying dynamic of EONIA volatility, the conditional mean and volatility of the EONIA

\footnotetext{
${ }^{2}$ See Figure A1 in the Appendix which shows that the EONIA spread level increased to about 65 basis points (negative) by the end of 2009 compared to the small positive spread in place prior to the collapse of Lehman Brothers. Figure A2 illustrates the decline of the EONIA rate within the ECB's standing facilities corridor.

${ }^{3}$ A small positive spread can be justified on the grounds that the marginal rate of the main refinancing operations is usually greater than the minimum bid rate. In addition, the EONIA rate can be greater than the MRO rate as collateral costs differ between the central bank and the market (see Linzert and Schmidt, 2008). Moreover, in noncrisis times, there is evidence to suggest that liquidity variables may only be relevant during the last week of the maintenance period - see, for example, Moschitz (2004), Ejerskov et al. (2003) and Würtz (2003).
} 
rate are estimated using an EGARCH model. ${ }^{4}$ Their analysis focuses on the period from March 2004 to August 2006. They find that the new framework has reduced the volatility in all money market rates. Interestingly they explain the fluctuations in the EONIA rate as being due to not only to the EONIA spread, but also to the term spread (defined as the spread between the 3month Euribor rate and the minimum bid rate). These authors find that the latter, as an indicator of interest rate expectations, is an important determinant, even under the new framework. Bartolini and Prati (2005) assess the volatility of overnight interest rates for a range of countries, including the euro area. These authors also use an EGARCH model and focus on the results from the variance equation to identify the effect of monetary policy implementation across countries on interest rate volatility.

Similarly, Würtz (2003) adopts an EGARCH specification to model the volatility of the EONIA spread, finding that expectations on changes in the policy rates and the end of the maintenance period effects are the main drivers of the EONIA spread. The equation used for the policy spread is non-linear to reflect the fact that the EONIA rate is bounded by the standing facilities of the ECB. Gaspar et al. (2008) present a model that examines the determinants of equilibrium in the market for daily funds. Using the EONIA panel database over the period 1999 to 2005, the model indicates that there is a rise in both the time series volatility and cross-section dispersion of the lending rates applied by commercial banks towards the end of the reserve maintenance period.

Sarno and Thornton (2003) apply an error-correction framework to US data. Specifically, the overnight rate is assessed by estimating error-correction equations for the Federal funds rate and the 3-month Treasury bill rate. They find that the adjustment of the Federal funds rate to the Treasury bill rate is asymmetric, namely that the effect is more pronounced when the Federal funds rate is below its equilibrium level. Similar effects in, respectively, a Japanese and European context have been found by Kuo and Enders (2004) and Clarida et al. (2006). Nautz and Offermanns (2007) examine how the EONIA rate adjusts to term interest spread, and how the policy rate of the ECB is affected by interest rate expectations and the monetary policy operational framework of the ECB. They find a strong role played by the tender arrangement. Specifically, the introduction of variable rate tenders with a minimum bid rate in June 2000 did not lead to a loss of control over the EONIA, and in fact, the link between EONIA and the policy rate appears to be even stronger when a positive spread is rising.

Previous research suggests that interest rate expectations had a strong role to play in driving the EONIA rate under the operational framework of the ECB that was in place prior to March 2004, whereas this was expected to have a much more muted effect under the post-March 2004 framework (see Bindseil et al., 2002). This was due to the fact that, under the new framework, the new policy rate would only become effective at the beginning of a new maintenance period after the meeting of the ECB Governing Council. ${ }^{5}$ Nautz and Offermanns (2007) make the point that the minimum bid rate of the ECB should set a lower-bound for interest rates, so that the adjustment of the EONIA to the policy rate should be stronger where the EONIA is low relative

\footnotetext{
${ }^{4}$ The estimation of an EGARCH model for assessing the volatility of overnight rates and the martingale hypothesis during the maintenance period was first carried out by Hamilton (1996), where the focus was on the Federal funds rate.

${ }^{5}$ This was intended to mitigate the distortive effects of interest rate expectations on the bidding by banks in the MRO and the overnight rate dynamics.
} 
to the minimum bid rate. ${ }^{6}$ This, in turn, suggests that there may be an asymmetric response in the EONIA spread to interest rate expectations. Such a scenario was identified for the euro area by Würtz (2003). In addition, in an application to the US, Sarno and Thornton (2003) indicate that expectations of rate rises have relatively stronger effects on overnight rates.

More recent research by Linzert and Schmidt (2008), based on OLS, finds that the EONIA spread is dependent upon liquidity policy (the difference between actual and benchmark allotment), the bid-to-cover ratio (the ratio between the total bid volume and the amount covered), within period rate expectations (the spread between one-week swap rates and the policy rate), interest rate uncertainty (the conditional volatility of the change in one-week swap rates), and the liquidity deficit. The results indicate that a rise in the liquidity deficit has a particularly strong effect in increasing the EONIA spread. A similar, albeit less strong, effect is found with banks' uncertainty over liquidity conditions, whereby greater uncertainty increases the spread.

Hassler and Nautz (2008) examine the persistence of the EONIA spread in an attempt to measure the controllability that the central bank has in maintaining a low spread. Like many other academic papers on the EONIA spread, this paper was written in the context of a rising spread following the change in the ECB's operational framework in March 2004. These authors use fractional integration techniques and interpret the order of fractional integration of the spread as a measure of the ability to control the overnight rate. ${ }^{7}$ With an interest in explaining why the EONIA spread appears to be non-responsive to liquidity injections by the ECB, they find that this may be due to a rise in persistence. Overall, they conclude that the spread is stationary prior to March 2004. After this period, it is fractionally integrated of an order of about 0.2. Thus, while they believe that the EONIA is still under control (with the order of integration being less than 0.5), the interpretation is that the extent of controllability may not be strong. This is of particular interest in the current paper, of course, where indeed controllability of the EONIA appears to have worsened considerably.

An apparent gap in the literature relates to the particular factors have affected the policy spread in the midst of the financial crisis of 2007 to 2009. The crisis caused this spread to rise substantially in the period after August 2007, and notably after the collapse of Lehman Brothers in September 2008. The interbank market in the euro area effectively broke down, as banks refused to lend to each other. In the euro area, they borrowed from the ECB and re-deposited with the ECB. This caused a change in the refinancing framework of the ECB, when in October 2008 it offered refinancing to banks at full allotment with a fixed rate for maturities up to 12 months. This expansion in liquidity provision was aimed at lowering borrowing costs as central banks acted as intermediaries for interbank market activity. The result was a substantial liquidity surplus in the Eurosystem and an associated rise in the central bank's balance sheet by a factor of about two, but also an apparent distortion of the signalling of the monetary policy stance. In the case of the UK, there has also been a liquidity surplus in place since October 2008, mainly owing to longer term refinancing against enlarged collateral for counterparties. Since March 2009, the

\footnotetext{
${ }^{6}$ In a related study, Ayuso and Repullo (2003) note that a central bank's asymmetric loss function may lead to a non-symmetric EONIA adjustment (in terms of, for example, a greater degree of risk aversion for an interest rate below rather than above target).

${ }^{7}$ They note that previous studies on the volatility of the EONIA spread have found it to be generated via an I $(0)$ data generating process (e.g., see Perez Quiros and Rodriguez Mendizabal, 2006) and Nautz and Offermanns, 2007). They view this approach, based on the dichotomy between integer order of integration, I(0) and I(1), as being overly restrictive.
} 
Bank of England has engaged in quantitative easing measures (asset purchases financed through central bank reserves).

We analyse the policy spread by estimating Stochastic Volatility models (see Harvey et al., 1994) for the spread as a function of the following factors in the case of both the euro area and the UK: liquidity risk (3-m EURIBOR/LIBOR-OIS spread), bank credit risk (bank CDS premia), sovereign credit risk (sovereign CDS premia), and interest rate expectations (1-m forward rate spread with the EURIBOR/LIBOR). All the data have been obtained from Bloomberg at a daily frequency over the period 7 August 2007 to 22 October 2009. Two models are estimated for the euro area and the UK in turn: one focusing on the less intense phase of the crisis (7 August 2007 to 14 September 2008), the other on the crisis after the collapse of Lehman Brothers (15 September 2008 to 22 October 2009).

Regarding the selection of our variables, we are aware of the fact that there may exist other measures, notably in relation to our measure for liquidity risk. We have opted for the spread between the benchmark unsecured interbank interest rate (EURIBOR or LIBOR rate) and the expected average of the overnight rate over the term of the loan (OIS rate). Arbitrage should imply a zero spread in these rates. The presence of a spread is indicative of tension in the interbank market. McAndrews et al (2009) makes the valid point that this spread can be decomposed into liquidity risk and credit risk components (although it can be difficult to disentangle). In the case of the US, they find that the spread is explained primarily by the noncredit risk component in non-crisis times. In addition, as the spread becomes higher and more volatile in crisis times, the credit risk component present is likely to reflect liquidity risk given that the CDS market becomes more illiquid in crisis times. Michaud and Upper (2008) also find that funding liquidity significantly explains the LIBOR-OIS spread. In addition, as noted by Hui et al. (2010), the LIBOR-OIS spread is the typical measure used by central banks and market participants as an indication of funding liquidity risks in the interbank market. ${ }^{8}$ As a result, we use this spread as our measure of liquidity risk. ${ }^{9}$

The layout of the remainder of the paper is the following. Section 2 outlines the econometric framework. Section 3 presents the empirical results. Section 4 summarises the main findings and draws some policy conclusions.

\section{The Econometric Framework}

We model the stochastic volatility of the overnight interest rate spread. Let $y_{t}$ denote the (demeaned) returns in the spread or the difference of logged spreads. This type of series will normally approximate a white noise process. Due to serial dependence in the variance, however, it may not necessarily be independent. This can be modelled as follows:

$$
\begin{array}{ll}
y_{t}=\beta_{1} x_{1 t}+\ldots+\beta_{p} x_{p t}+\sigma \varepsilon_{t} \exp \left(h_{t} / 2\right) & \varepsilon_{\mathrm{t}} \sim \operatorname{IID}(0,1), \mathrm{t}=1, \ldots \ldots, \mathrm{T} . \\
\text { where } \mathrm{h}_{\mathrm{t}}=\phi \mathrm{h}_{\mathrm{t}-1}+\eta_{\mathrm{t}} & \eta_{\mathrm{t}} \sim \mathrm{NID}\left(0, \sigma_{\eta}^{2}\right),|\phi| \leq 1
\end{array}
$$

\footnotetext{
${ }^{8}$ For example, see the Bank of England's Financial Stability Report (June 2009, No. 25) and the IMF's Global Financial Stability Report (April 2009).

${ }^{9}$ It should be noted that the distinction between liquidity risk (the risk that assets cannot be converted into cash) and credit risk (the risk that a bank may fail to meet its contractual obligations) is unclear. Indeed, von Thadden (1999) has made the point that "the definition of liquidity is elusive".
} 
In this framework, $\left\{\mathrm{x}_{\mathrm{it}} ; \mathrm{i}=1, \ldots \ldots, \mathrm{p}\right\}$ are explanatory variables, $\mathrm{h}_{\mathrm{t}}$ is a vector of unobservable factors, whose dynamics are modelled as a random walk as in (2). $\sigma^{2}$ is a scale factor, $\phi$ is a parameter, and $\eta_{\mathrm{t}}$ is a disturbance term which is not correlated with $\varepsilon_{\mathrm{t}}$. A series of stochastic volatility models will be estimated here based on the framework described, where the observable variables driving the volatility spread are the volatilities of liquidity risk, bank credit risk, sovereign credit risk, and interest rate expectations. The models also incorporate unobserved components to account for a stochastic trend, cyclicality, and irregularity, as well as a first-order autoregressive component.

As described in Koopman et al. (2000), this type of stochastic volatility model represents the natural discrete time analogue of the continuous time model used in the financial economics literature (e.g. Hull and White, 1987). The other main positive feature of this model is that its statistical properties are easy to determine. The series is transformed based on the following Taylor series:

$$
\log y_{t}^{2} \cong \log \left(y_{t}^{2}+c s_{y}^{2}\right)-c s_{y}^{2} /\left(y_{t}^{2}+c s_{y}^{2}\right)
$$

where $\mathrm{y}_{\mathrm{t}}$ is a given time series, $\mathrm{s}_{\mathrm{y}}^{2}$ is the sample variance of $\mathrm{y}_{\mathrm{t}}$, and $\mathrm{c}$ is a small number (a value of 0.02 is suggested). ${ }^{10}$ The vast majority of stochastic volatility models have found that $\phi$ is close to one, implying a similar model fit to that of a $\operatorname{GARCH}(1,1)$ model. The above set-up can easily be extended to the multivariate case (e.g. Harvey et al., 1994), where in order to investigate the dynamic interactions between the various volatilities one can let the vector of volatilities $h_{t}$ follow a VAR(1) process. Specifically, two alternative models will be estimated for the euro area and the UK, as follows:

- Crisis Pre-Lehman Collapse: 7 August 2007 to 14 September 2008

- Crisis Post-Lehman Collapse: 15 September 2008 to 22 October 2009

The dates have been selected to coincide with well-known events and also to ensure an equal number of observations in each model. Using this approach provides us with an overview of whether the policy spread drivers behave differently in different crisis stages. For example, the post-Lehman collapse phase provides a special case in which basically all of the euro area's banking sector's refinancing needs were met by the Eurosystem, which caused the EONIA rate to drop below the policy rate after that (since the cost of refinancing for banks with access to the money market (EONIA) was much lower than the rate applied to banks that needed to go to the Eurosystem).

\section{Empirical Results}

This section reports the estimation results. The models are conditioned on the spread between the overnight interest rate and the main central bank policy rate. Tables 1 and 2 provide, respectively, the results for the euro area in the less intense period of the crisis and the phase of the crisis after the collapse of Lehman Brothers. ${ }^{11}$

\footnotetext{
${ }^{10}$ This is the transformation suggested by Breidt and Carriquiry (1996) to deal with a practical problem arising if the expression in (3) is given by $\log y_{t}^{2}$. In this case some of the observations are zero, and the logarithm cannot be taken.

${ }^{11}$ Diagnostic test results indicate that the chosen model specifications are satisfactory (see Table A1 in the Appendix).
} 
Table 1 Crisis Period in Less Intense Phase - Euro Area

\begin{tabular}{|c|c|c|c|c|}
\hline \multicolumn{5}{|c|}{ Stochastic Volatility Model Output } \\
\hline & Coefficient & SE & t-value & prob \\
\hline Liquidity Risk & $0.837 * * *$ & 0.041 & 20.191 & {$[0.000]$} \\
\hline Bank Credit Risk & $0.035 * * *$ & 0.013 & 2.637 & {$[0.009]$} \\
\hline Sovereign Credit Risk & $0.085 * *$ & 0.042 & 2.027 & {$[0.044]$} \\
\hline Interest Rate Expectations & -0.014 & 0.020 & -0.731 & {$[0.465]$} \\
\hline \multicolumn{5}{|l|}{ Variance of Disturbances } \\
\hline Component & \multicolumn{2}{|c|}{ Value } & \multicolumn{2}{|c|}{ (q-ratio) } \\
\hline Level & \multicolumn{2}{|c|}{0.003} & \multicolumn{2}{|c|}{$(0.010)$} \\
\hline Slope & \multicolumn{2}{|c|}{0.000} & \multicolumn{2}{|c|}{$(0.000)$} \\
\hline Cycle & \multicolumn{2}{|c|}{0.000} & \multicolumn{2}{|c|}{$(0.000)$} \\
\hline $\mathrm{AR}(1)$ & \multicolumn{2}{|c|}{0.363} & \multicolumn{2}{|c|}{$(1.000)$} \\
\hline Irregular & \multicolumn{2}{|c|}{0.000} & \multicolumn{2}{|c|}{$(0.000)$} \\
\hline \multicolumn{5}{|l|}{ Parameters in AR(1) } \\
\hline Variance & \multicolumn{4}{|c|}{0.363} \\
\hline AR(1) Coefficient & \multicolumn{4}{|c|}{0.105} \\
\hline
\end{tabular}

Table 2 Crisis in Post-Lehman Collapse Phase - Euro Area

\begin{tabular}{|c|c|c|c|c|}
\hline \multicolumn{5}{|c|}{ Stochastic Volatility Model Output } \\
\hline & Coefficient & SE & t-value & prob \\
\hline Liquidity Risk & $0.429 * * *$ & 0.070 & 6.095 & {$[0.000]$} \\
\hline Bank Credit Risk & $0.238 * * *$ & 0.071 & 3.340 & {$[0.001]$} \\
\hline Sovereign Credit Risk & 0.027 & 0.052 & 0.532 & [0.595] \\
\hline Interest Rate Expectations & -0.035 & 0.058 & -0.609 & {$[0.543]$} \\
\hline \multicolumn{5}{|l|}{ Variance of Disturbances } \\
\hline Component & \multicolumn{2}{|c|}{ Value } & \multicolumn{2}{|c|}{ (q-ratio) } \\
\hline Level & \multicolumn{2}{|c|}{0.000} & \multicolumn{2}{|c|}{$(0.000)$} \\
\hline Slope & \multicolumn{2}{|c|}{0.000} & \multicolumn{2}{|c|}{$(0.000)$} \\
\hline Cycle & \multicolumn{2}{|c|}{0.004} & \multicolumn{2}{|c|}{$(0.006)$} \\
\hline $\mathrm{AR}(1)$ & \multicolumn{2}{|c|}{0.810} & \multicolumn{2}{|c|}{$(1.000)$} \\
\hline Irregular & \multicolumn{2}{|c|}{0.396} & \multicolumn{2}{|c|}{$(0.489)$} \\
\hline \multicolumn{5}{|l|}{ Parameters in AR(1) } \\
\hline Variance & \multicolumn{4}{|c|}{0.809} \\
\hline AR(1) Coefficient & \multicolumn{4}{|c|}{0.841} \\
\hline
\end{tabular}

For the euro area, in the less intense phase of the crisis, the volatility in the EONIA spread is driven almost fully by liquidity risk. However, both private bank credit risk and sovereign credit risk also appear to play a role. Interest rate expectations do not affect the volatility of the spread, 
which is perhaps indicative of a high degree of market certainty on interest rate changes at the ECB. Table 2 shows that the EONIA spread volatility in the post-Lehman phase of the crisis is driven by both liquidity risk and private bank credit risk. Interestingly, liquidity risk seems to play a lesser role in this phase of the crisis compared with the less intense phase, while bank credit risk assumes a much more substantial role in affecting the volatility of the spread. In addition, sovereign credit risk in the post-Lehman phase no longer affects the volatility spread. This may suggest that, despite the non-conventional monetary policy measures introduced by the ECB to address liquidity funding needs, as the crisis intensified bank CDS premia increased due to possible default fears amongst market participants.

The variance of the disturbances reported conveys information on the fluctuations in the model components. The results suggest that there is no evidence of an unobserved stochastic trend in the model, implying that the variables used in the model are sufficient and other exogenous variables that cannot be explicitly measured are not required. ${ }^{12}$ In addition, there is no evidence of unobserved cyclical behaviour in the less intense phase, and only marginal evidence in the post-Lehman phase. Unlike in the less intense phase, there is evidence of the presence of an unobserved irregular component in the phase of the crisis after the collapse of Lehman Brothers. This is in line with intuition. In addition, there is a notable rise in the size of the autoregressive coefficient from the less intense phase to the post-Lehman phase, indicative of greater persistence in the latter period. Finally, as shown in Figures A3 and A4 in the Appendix, the onestep ahead filter appears to have a better fit in the less intense phase of the crisis, in line with expectations. ${ }^{13}$ Tables 3 and 4 below present the results for the UK.

Table 3 Crisis Period in Less Intense Phase - UK

\begin{tabular}{|c|c|c|c|c|}
\hline \multicolumn{5}{|c|}{ Stochastic Volatility Model Output } \\
\hline & Coefficient & SE & t-value & prob \\
\hline Liquidity Risk & $0.185 * * *$ & 0.063 & 2.928 & {$[0.004]$} \\
\hline Bank Credit Risk & $0.075 * * *$ & 0.051 & 1.460 & {$[0.001]$} \\
\hline Sovereign Credit Risk & -0.026 & 0.023 & -1.158 & [0.248] \\
\hline Interest Rate Expectations & 0.178 & 0.052 & 3.379 & {$[0.145]$} \\
\hline \multicolumn{5}{|l|}{ Variance of Disturbances } \\
\hline Component & \multicolumn{2}{|c|}{ Value } & \multicolumn{2}{|c|}{ (q-ratio) } \\
\hline Level & \multicolumn{2}{|c|}{0.000} & \multicolumn{2}{|c|}{$(0.000)$} \\
\hline Slope & \multicolumn{2}{|c|}{0.000} & \multicolumn{2}{|c|}{$(0.000)$} \\
\hline Cycle & \multicolumn{2}{|c|}{0.000} & \multicolumn{2}{|c|}{$(0.000)$} \\
\hline $\mathrm{AR}(1)$ & \multicolumn{2}{|c|}{0.549} & \multicolumn{2}{|c|}{$(0.766)$} \\
\hline Irregular & \multicolumn{2}{|c|}{0.718} & \multicolumn{2}{|c|}{$(1.000)$} \\
\hline \multicolumn{5}{|l|}{ Parameters in AR(1) } \\
\hline Variance & \multicolumn{4}{|c|}{0.549} \\
\hline AR(1) Coefficient & \multicolumn{4}{|c|}{0.866} \\
\hline
\end{tabular}

\footnotetext{
${ }^{12}$ There are two components to the trend: the level is the actual value of the trend, while the slope is the component of the trend that may or may not be present. When the estimated value of the parameters is zero, this implies that a stochastic trend is not present.

${ }^{13}$ This filter is the one-step ahead prediction error, which provides the minimum mean square linear estimators of $h_{t}$ and future observations (as opposed to the minimum mean square estimators (since $\log y_{t}^{2}$ is not strictly Gaussian).
} 
Table 4 Crisis in Post-Lehman Collapse Phase - UK

\begin{tabular}{|c|c|c|c|c|}
\hline \multicolumn{5}{|c|}{ Stochastic Volatility Model Output } \\
\hline & Coefficient & SE & t-value & prob \\
\hline Liquidity Risk & $0.129 * *$ & 0.053 & 2.422 & {$[0.016]$} \\
\hline Bank Credit Risk & -0.015 & 0.059 & -0.259 & [0.795] \\
\hline Sovereign Credit Risk & 0.015 & 0.055 & 0.271 & {$[0.787]$} \\
\hline Interest Rate Expectations & $0.121 * *$ & 0.056 & 2.138 & [0.033] \\
\hline \multicolumn{5}{|l|}{ Variance of Disturbances } \\
\hline Component & \multicolumn{2}{|c|}{ Value } & \multicolumn{2}{|c|}{ (q-ratio) } \\
\hline Level & \multicolumn{2}{|c|}{0.001} & \multicolumn{2}{|c|}{$(0.001)$} \\
\hline Slope & \multicolumn{2}{|c|}{0.000} & \multicolumn{2}{|c|}{$(0.000)$} \\
\hline Cycle & \multicolumn{2}{|c|}{0.002} & \multicolumn{2}{|c|}{$(0.003)$} \\
\hline $\mathrm{AR}(1)$ & \multicolumn{2}{|c|}{0.434} & \multicolumn{2}{|c|}{$(0.768)$} \\
\hline Irregular & \multicolumn{2}{|c|}{0.565} & \multicolumn{2}{|c|}{$(1.000)$} \\
\hline \multicolumn{5}{|l|}{ Parameters in AR(1) } \\
\hline Variance & \multicolumn{4}{|c|}{0.434} \\
\hline AR(1) Coefficient & \multicolumn{4}{|c|}{0.612} \\
\hline
\end{tabular}

In this case, in the less intense phase of the crisis, liquidity risk and private bank credit risk significantly affect the volatility of the UK overnight interest rate spread (the SONIA spread, SONIA standing for sterling overnight interest rate average). In addition, as in the case of the $\mathrm{ECB}$, it seems that market participants fully priced in interest rate fluctuations, and therefore these do not affect the SONIA spread volatility. Unlike in the euro area, however, sovereign credit risk is not significant. Indeed, this may be a function of the heterogeneity of credit risk characteristics across many countries and firms in the euro area, whereas UK banks have relatively similar risk characteristics. Table 4 shows that liquidity risk and interest rate expectations drive the SONIA spread volatility in the post-Lehman phase. The fact that interest rate expectations are significant suggests that the market was uncertain about the future path of UK interest rates. The lack of significance in the bank credit risk measure in this phase of the crisis is likely to be related to the bank rescue package announced by the UK government in October 2008, totally some GBP500 million.

The variance of the disturbances indicates that, as in the case of the euro area, there is no evidence of an unobserved stochastic trend in the model across both phases of the crisis. In addition, as in the case of the euro area, there is some very marginal evidence of an unobserved cyclical component in the post-Lehman phase. The autoregressive coefficient is high in both phases, although somewhat higher in the less intense crisis phase, implying less persistence in the post-Lehman phase. In addition, there is some evidence of an irregular component across both sub-periods for the UK (unlike the euro area, where this was only the case for the phase of the crisis after the collapse of Lehman Brothers). This may be related to distortions relating to the emergency bail-out of Northern Rock in September 2007, one of the UK's largest mortgage lenders at the time. This may also be a contributory factor to the apparent poor fit of the one-step ahead filter for the UK (see Figures A5 and A6 in the Appendix). 
In interpreting these results, it is worth bearing in mind that the immediate response to the crisis by the ECB was different from that of the Bank of England. At the onset of the crisis in August 2007, the ECB opted to inject additional liquidity into the market via open market operations in order to avoid a spike in short-term interest rates. By contrast, the Bank of England provided liquidity through its overnight lending facility, which caused a rise in overnight rates. In addition, differences in responses were related to different operational frameworks in place. The ECB usually operates with 300 banks, although 1700 can access open market operations and an additional 700 can access overnight standing facilities. By contrast, the Bank of England deals with just 40 counterparties, with a further 20 being able to access standing facilities. Moreover, the collateral framework in place at the onset of the crisis meant that the effective provision of liquidity was more fluid in the case of the ECB compared with the Bank of England. For example, the ECB already had in place a wide definition of eligible collateral. In the case of the Bank of England, it was necessary to make adjustments to instruments to accept a broader set of collateral. It is clear that the ECB had a particular advantage over the Bank of England given its access to a much wider range of counterparties. The operational structures in place at the ECB may help to explain why the extent to which liquidity risk affected the spread in the first phase of the crisis was reduced by about half in the second phase (compared to the UK, where there was no change in the extent to which liquidity risk affected volatility in the policy spread).

\section{Conclusions}

This paper has estimated a stochastic volatility model for the overnight interest rate spread for the euro area and the UK during the financial crisis which began in August 2007, focusing on the role played by liquidity risk, bank credit risk, sovereign credit risk, and interest rate expectations. Two models were estimated for the euro area and the UK in turn, one examining the period from the inception of the crisis in August 2007 until September 2008, and the other the subsequent period when the crisis intensified following the collapse of Lehman Brothers in September 2008.

The results suggest that liquidity risk is the primary determinant of the volatility in the policy spread. This holds across both phases of the crisis for the euro area and the UK. In the case of the euro area, it is apparent that the role played by liquidity risk declined in the post-Lehman collapse phase compared to the less intense phase of the crisis. This suggests that the liquidity easing measures introduced by the ECB have helped to address funding liquidity stress in the market. By contrast, bank credit risk has become a more substantial driver of volatility in the policy spread in the post-Lehman phase. This may suggest that while liquidity risk was alleviated, the role played by bank credit risk became more substantial then. This may be related to fears of bank default by the market as collateral eligibility was broadened. Regarding the UK, the extent of liquidity risk has remained largely constant across both crisis phases, while bank credit risk was eliminated in the post-Lehman phase. As for the role of interest rate expectations, these do not appear to affect volatility in the policy spread for the euro area, suggesting effective communication on the part of the ECB. However, interest rate expectations are significant in the post-Lehman phase in the UK, suggesting some uncertainty or lack of transparency by the Bank of England as regards policy signalling.

Overall, it appears that the volatility in the policy spread is largely associated with liquidity risk and bank credit risk. This is particularly the case for the euro area, where there exists a more heterogenous group of banks and a more heterogenous set of risk characteristics in the banking sector compared to the UK. The overarching motivation for a central bank's preference for a 
non-volatile spread relates to the signalling of the monetary policy stance. Excessive volatility in the spread can distort the stance of monetary policy in the market. Given this, the main policy implication of our analysis would be that control of the volatility in the policy spread requires prudent central bank intermediation, but also, crucially, a sufficiently flexible operational framework for monetary policy implementation. The flexibility in the ECB's framework enabled it to react rapidly to tensions in the market to address liquidity concerns. This may help to explain why the extent to which liquidity risk affected the volatility of the policy spread in the euro area almost halved in the post-Lehman collapse phase of the crisis compared to the first stage of the crisis. 


\section{References}

Ayuso, J., and Repullo, R. (2003), "A Model of the Open Market Operations of the European Central Bank”, Economic Journal, 113, pp. 883-902.

Bartolini, L. and Prati, A. (2005), "Cross-Country Differences in Monetary Policy Execution and Money Market Rates' Volatility”, European Economic Review, 50(2), pp. 349-376.

Bindseil, U., Nyborg, K. and Strebulav, I. (2002), "Bidding Performance in Repo Auctions: Evidence from the ECB Open Market Operations", ECB Working Paper No. 157.

Breidt, F.J. and Carriquiry, A. L. (1996): "Improved quasi-maximum likelihood estimation for stochastic volatility models", in Jack C. Lee, W.O. and Zellner, A. (eds.), Modelling and Prediction: Honouring Seymour Geisser, pp. 228-47. New York: Springer-Verlag.

Clarida, R.H., Sarno, L., Taylor, M.P. and Valente, G. (2006), "The Role of Asymmetries and Regime Shifts in the Term Structure of Interest Rates", Journal of Business, 79(3), pp. 11931224.

Ejerskov, S., Moss, C.M. and Stracca, L. (2003), "How does the ECB Allot Liquidity in its Weekly Main Refinancing Operations? A Look at the Empirical Evidence", ECB Working Paper No. 244.

Gaspar, V., Perez Quiros, G., and Rodriguez Mendizabal, H. (2008), "Interest Rate Dispersion and Volatility in the Market for Daily Funds", European Economic Review, 52, pp. 413-440.

Hamilton, J. (1996), “The Daily Market for Federal Funds”, Journal of Political Economy, 104, pp. 26-56.

Harvey, A. C. (1989): Forecasting, Structural Time Series Models and the Kalman Filter, Cambridge University Press, Cambridge.

Harvey, A.C., Ruiz, E. and Shephard, N. (1994): "Multivariate stochastic variance models", Review of Economic Studies, 61, 247-264.

Hassler, U. and Nautz, D. (2008), "On the Persistence of the EONIA Spread", Economics Letters, 101 (3), pp. 184-187.

Hui, C., Genberg, H., and Chung, T. (2010), "Funding Liquidity Risk and Deviations from Interest-Rate Parity During the Financial Crisis of 2007-2009", International Journal of Finance and Economics, forthcoming.

Koopman, S.J., Harvey, A.C., Doornik, J.A., and Shephard, N. (2000), STAMP - Structural Time Series Analyser, Modeller and Predictor, Timberlake Consultants, UK.

Kuo, S.H. and Enders, W. (2004), "The Term Structure of Japanese Interest Rates: The Equilibrium Spread with Asymmetric Dynamics", Journal of the Japanese and International Economies, 18, pp. 84-98. 
Linzert, T. and Schmidt, S. (2008), "What Explains the Spread between the Euro Overnight Rate and the ECB's Policy Rate", ECB Working Paper No. 983.

McAndrews, J., Sarkar, A., and Wang, Z. (2009), "The Effect of the Term Auction Facility on the London Inter-Bank Offered Rate”, Staff Reports 335, Federal Reserve Bank of New York.

Michaud, F.M. and Upper, C. (2008), "What Drives Interbank Rates? Evidence from the LIBOR Panel”, BIS Quarterly Review, pp. 47-58.

Moschitz, J. (2004), “The Determinants of the Overnight Interest Rate in the Euro Area”, ECB Working Paper No. 393.

Nautz, D. and Offermanns, C.J. (2007), "The Dynamic Relationship between the Euro Overnight Rate, the ECB's Policy Rate and the Term Spread", International Journal of Finance and Economics, 12, pp. 287-300.

Nautz, D. and Offermanns, C.J. (2008), "Volatility Transmission in the European Money Market”, North American Journal of Economics and Finance, 19, pp. 23-39.

Perez Quiros, G. and Rodriguez Mendizabal, H. (2006), “The Daily Market for Funds in Europe: What has Changed with EMU?", Journal of Money, Credit, and Banking, 38(1), pp. 91-118.

Von Thadden, E. (1999), "Liquidity Creation through Banks and Markets: Multiple Insurance and Limited Market Access", European Economic Review, 43 (4-6), pp. 991-1006.

Würtz, F. (2003), “A Comprehensive Model on the Euro Overnight Rate”, ECB Working Paper No. 207. 


\section{Appendix}

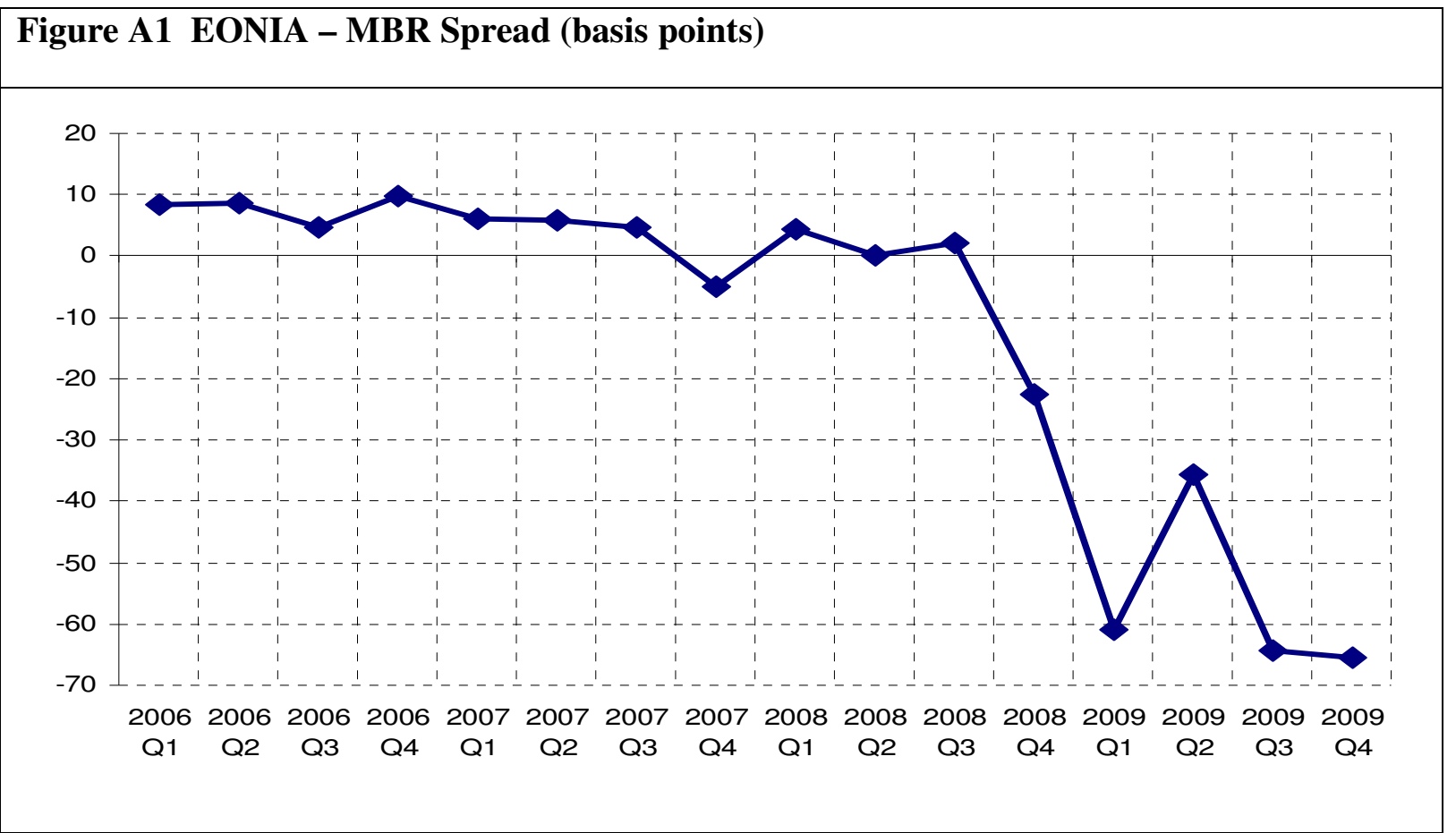

Note: MBR stands for the minimum bid rate (MBR) in the main refinancing operations (MRO).

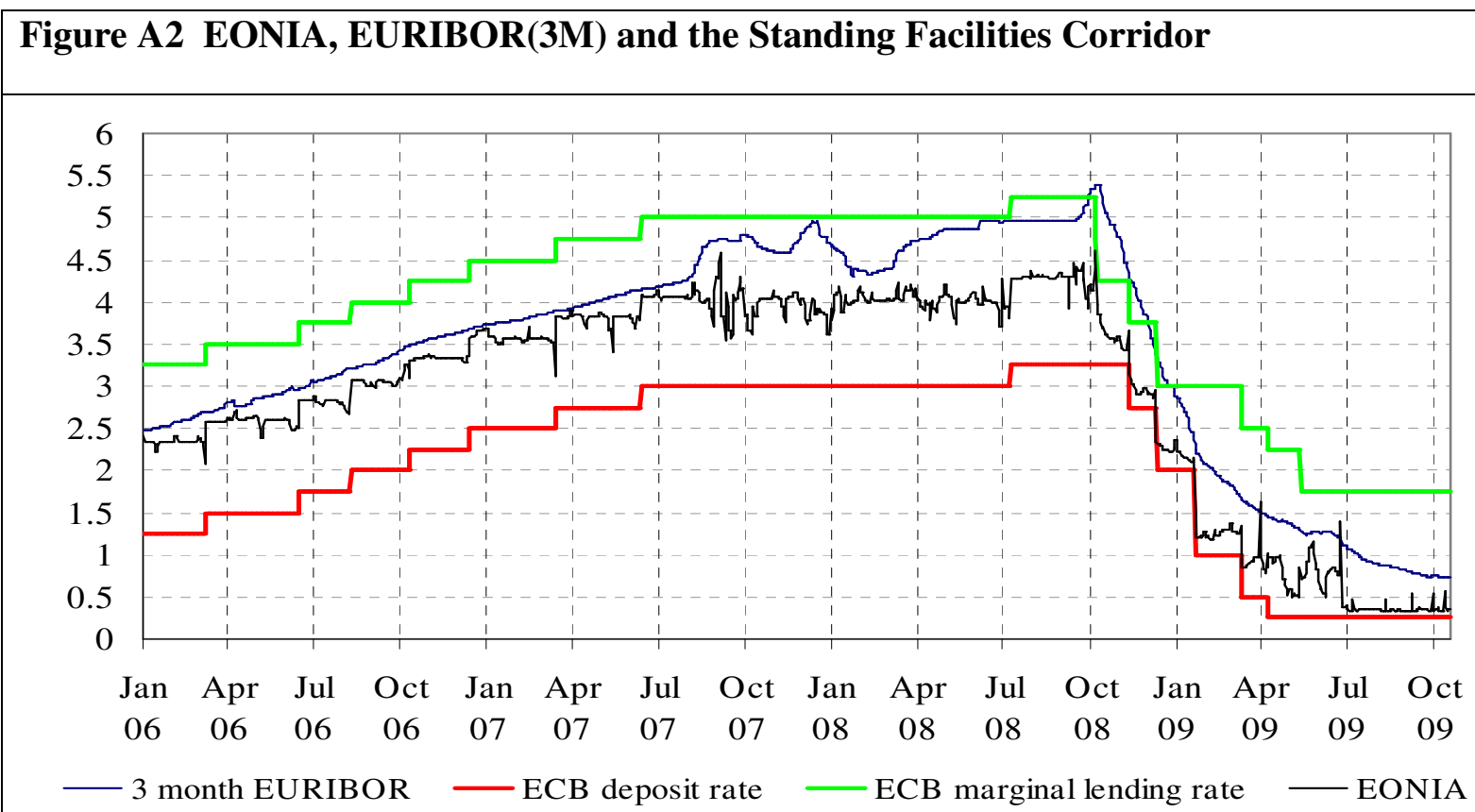

Note: the standing facilities corridor is defined by the interest rate on the marginal lending facility (MLF) to obtain overnight liquidity from the ECB and the interest rate on the deposit facility (DF) to make overnight deposits, which normally provide the ceiling and floor for the overnight market interest rate. 
Table A1 Model Test Diagnostics

\begin{tabular}{|l|l|l|l|l|}
\hline \multirow{2}{*}{ Summary Diagnostics } & \multicolumn{2}{|c|}{ Euro Area } & \multicolumn{3}{c|}{ UK } \\
\cline { 2 - 5 } & $\begin{array}{l}\text { Less Intense } \\
\text { Crisis Phase }\end{array}$ & $\begin{array}{l}\text { Crisis Post } \\
\text { Lehman }\end{array}$ & $\begin{array}{l}\text { Less Intense } \\
\text { Crisis Phase }\end{array}$ & $\begin{array}{l}\text { Crisis Post } \\
\text { Lehman }\end{array}$ \\
\hline Standard Error & 0.635 & 0.991 & 1.009 & 0.983 \\
\hline Normality & 53.935 & 7.414 & 4.543 & 25.695 \\
\hline Heteroskedasticity & 0.308 & 0.419 & 0.885 & 0.816 \\
\hline Serial Correlation at lag 1: r(1) & 0.006 & -0.004 & -0.008 & -0.010 \\
\hline Serial Correlation at lag 14: r(14) & 0.078 & -0.029 & -0.063 & -0.023 \\
\hline Durbin-Watson & 1.979 & 2.004 & 1.964 & 1.999 \\
\hline Box-Ljung-Q Q(14,10) & 10.242 & 3.396 & 7.240 & 6.832 \\
\hline R-squared & 0.799 & 0.464 & 0.363 & 0.401 \\
\hline
\end{tabular}

Figure A3 Stochastic Volatility of the Spread and One Step-Ahead Filter, Euro Area

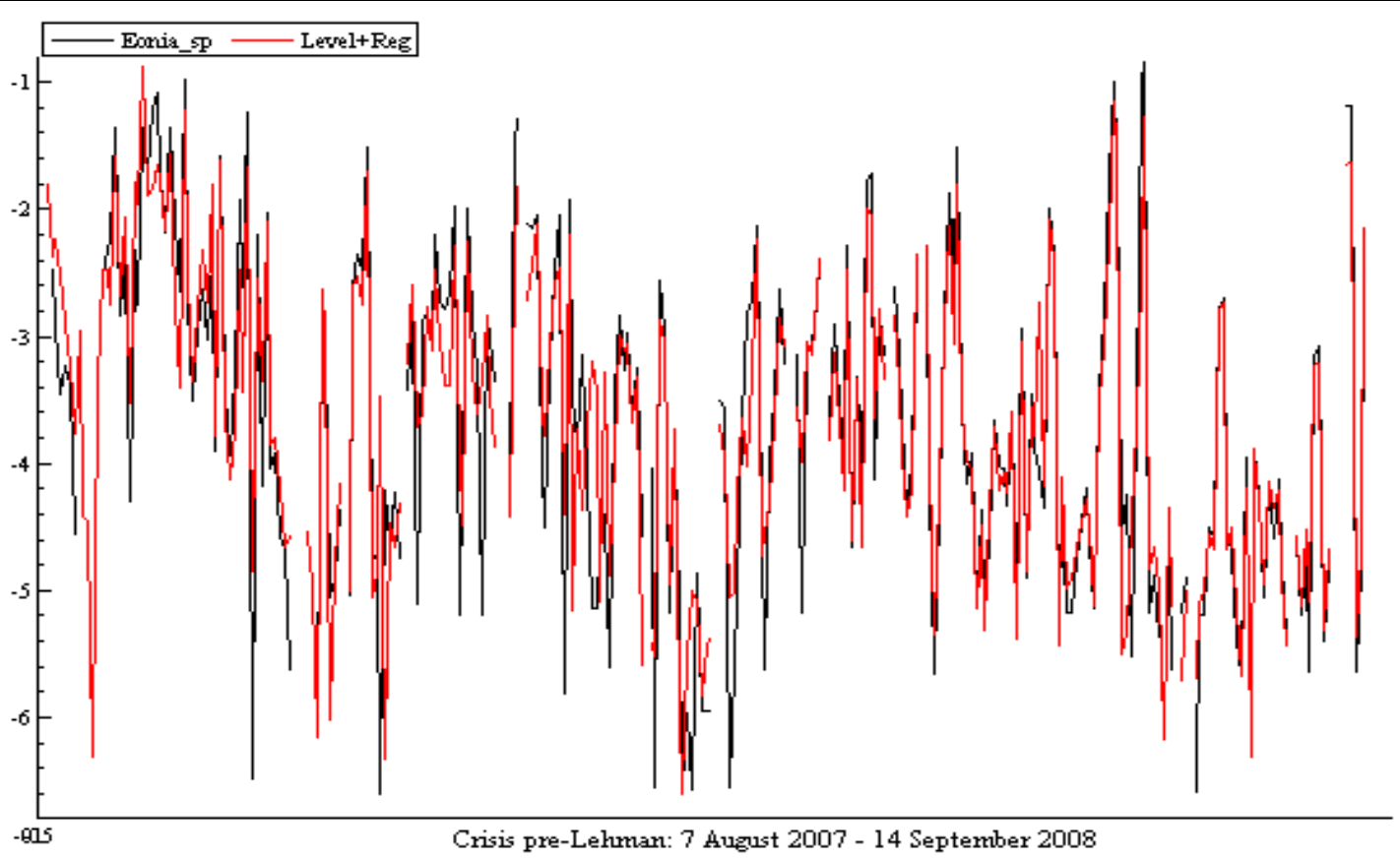


Figure A4 Stochastic Volatility of the Spread and One Step-Ahead Filter, Euro Area

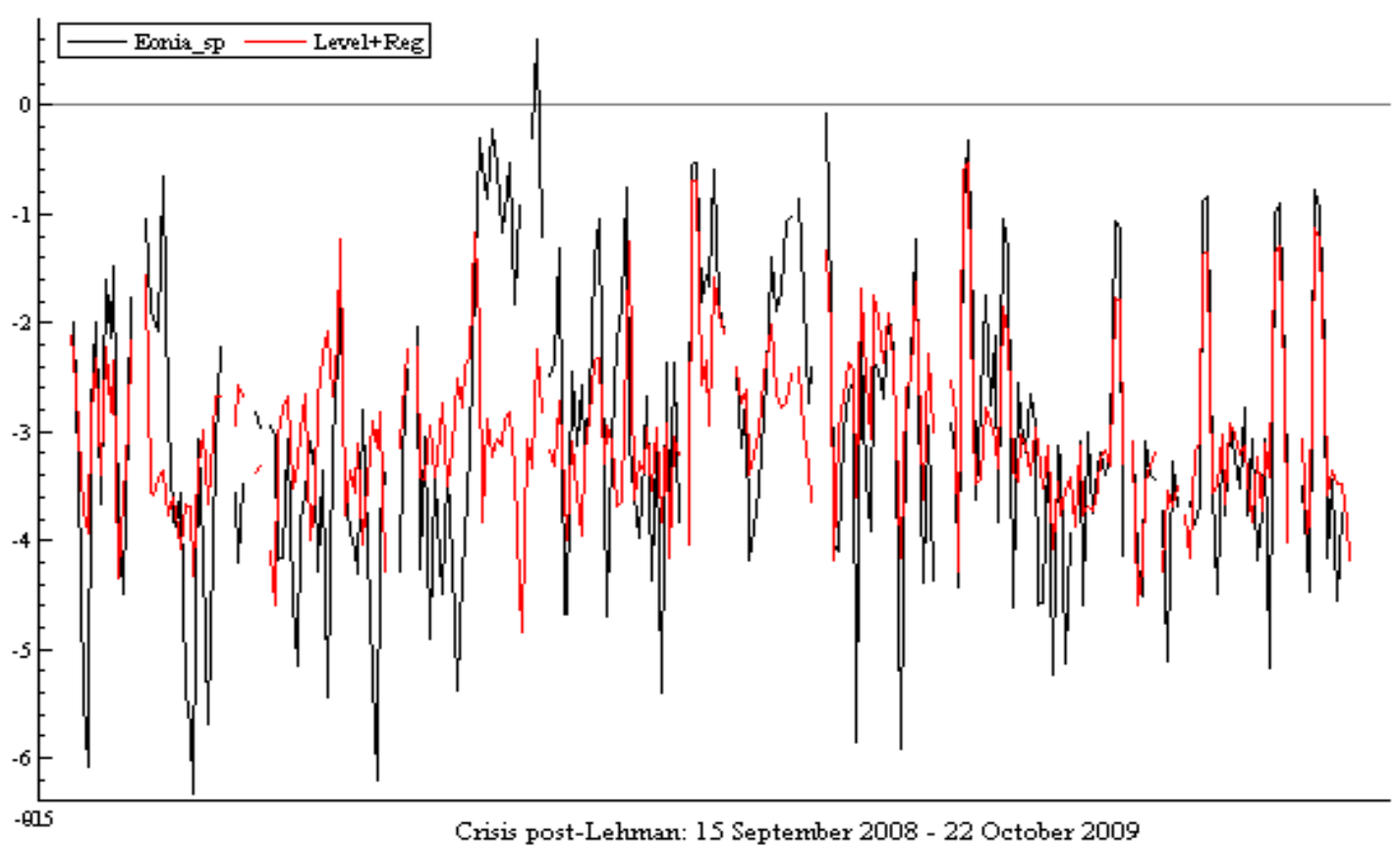

Figure A5 Stochastic Volatility of the Spread and One Step-Ahead Filter, UK

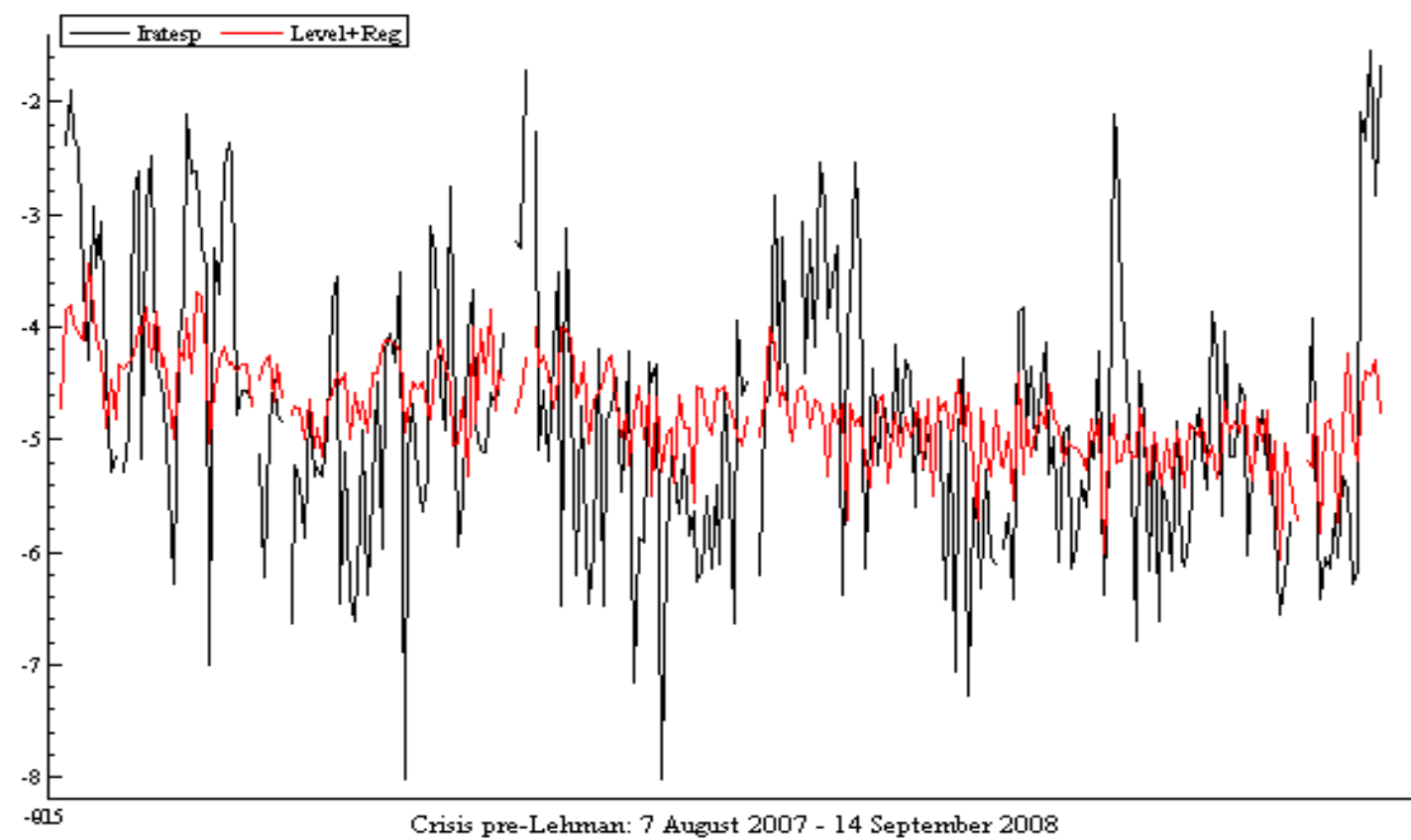


Figure A6 Stochastic Volatility of the Spread and One Step-Ahead Filter, UK

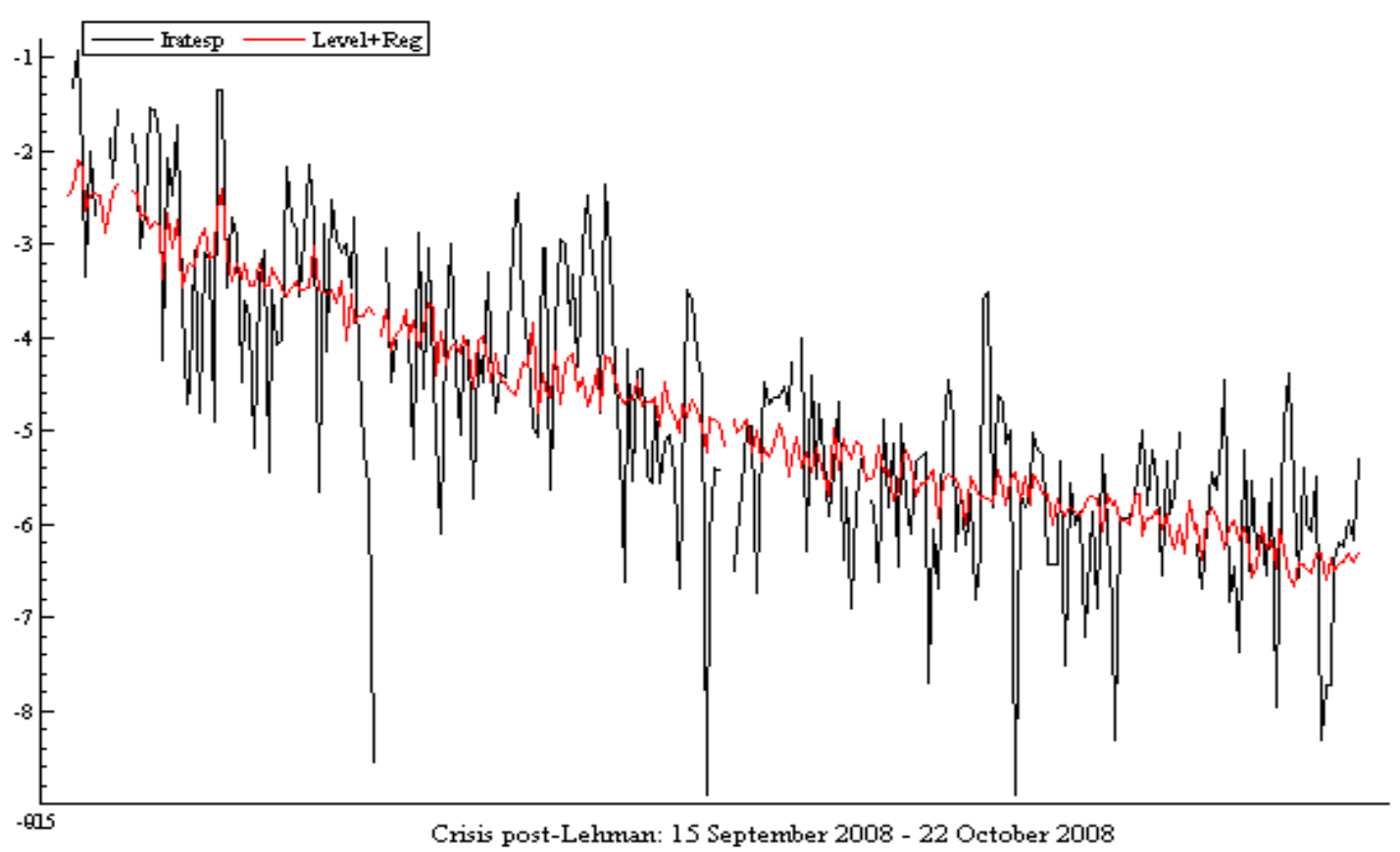

